\title{
Características de individuos que vivenciaram o êxodo rural em um município da fronteira-oeste do RS
}

Characteristics of people who experienced rural exodus in a town on the western border of the state of Rio Grande do Sul

Rosane Maria Kirchner'; Ana Paula Fleig Saidelles²; Nara Zamberlan dos Santos; Joana Kirchner Benetti'; Eniva Miladi Stumm ${ }^{5}$

'CERNORS/Universidade Federal de Santa Maria. Campus Palmeira das Missões/RS

${ }^{2}$ UNIPAMPA

${ }^{3}$ UNIPAMPA/Universidade Federal do Pampa. Campus São Gabriel/RS

${ }^{4}$ Professora do Departamento de Ciências Exatas e Engenharias da Universidade Regional do Noroeste do RS-UNIJUI.

${ }^{5}$ Professora do Departamento de Ciências da Saúde da Universidade Regional do Noroeste do RS-UNIJUI.

\section{Resumo}

A crescente migração campo-cidade registrada no século passado impôs uma serie de dificuldades a estes trabalhadores e uma adaptação as condições urbanas. A pesquisa quantitativa, descritiva, estudo de caso, realizada e município São Gabriel, Fronteira-Oeste do Rio Grande do Sul, pertencente à Metade Sul do estado foi desenvolvida junto a cidadãos que abandonaram o campo. Os resultados demonstraram que os entrevistados hoje desenvolvem atividades tanto como empregados e como autônomos. Ainda é percebido o emprego informal e a dificuldade de escolas para os filhos, porém a maioria possui casa própria. Os dados confirmam as dificuldades enfrentadas por estes migrantes, mas também os esforços empreendidos para atenuar as desigualdades impostas pela sociedade.

Palavras-chave: Migração, campo-cidade, São Gabriel.

\begin{abstract}
The increasing migration of people from countryside to the cities, registered in the past century, caused a series of difficulties to these workers and required their adaptation to urban conditions. The quantitative and descriptive research, case study, carried out in São Gabriel City, western border of the State of Rio Grande do Sul, located in the southern half of the state, was developed amongst citizens who moved from countryside to the urban area. Results showed that the enterviewed people nowadays develop actitivies as autonomous workers and as employees. Results also showed that, although part of the enterviewed people have informal jobs and face difficulties to find schools for their children, most of them own their own houses. The data confirms the difficulties faced by these people, but also demonstrates the efforts to minimize inequalities imposed by society.
\end{abstract}

Keywords: Migration, countryside-city, São Gabriel City. 


\section{INTRODUCÃO}

O êxodo rural é o abandono do campo em busca das cidades. Estas em fase de crescimento e de industrialização oferecem melhores condições de trabalho e de vida. A procura dessas condições, milhares de retirantes abandonam o meio rural se aventurado no meio urbano. A cada publicação censitária, o resultado é o mesmo: prossegue o esvaziamento e envelhecimento do meio rural. Em termos nacionais, a intensidade do movimento de desruralização é evidente nas ultimas décadas, aumentando a população nas cidades, isto ocorre, pelas mudanças nos processos produtivos e nas relações sociais da vida rural, onde, muitas vezes atividades não-agrícolas são desenvolvidas para complementação da renda da família.

Para Roth et al. (2006), as condições de trabalho e a renda nem sempre são atrativas para determinadas faixas etárias, fazendo com que o êxodo rural e o envelhecimento da população rural, tornem-se situações cada vez mais freqüentes.

A modernização da agricultura no Brasil relacionado a um novo padrão de desenvolvimento econômico demonstrou segundo Balsan (2006), a exclusão do homem do campo trazendo como conseqüência a desordem do espaço rural.

O período de 1950 e 2000, principalmente, nas áreas rurais é apontado por Morais (2007) como de maior volume de migrantes em direção as áreas urbanas. Neste contexto, Sulzbacher e David (2007) salientam que a monocultura da soja no Estado, bem como surgimento da transgênica, tiveram grande impacto ambiental e no êxodo rural.

A sociedade nas últimas décadas impôs a leitura que o meio rural significa a falta de oportunidades, a estagnação e o atraso, ao contrário do meio urbano visto como aberto às oportunidades e ao progresso. Porém, este enfoque esconde toda a sorte de incertezas, de abandono e de discriminação que o homem rural poderá encontrar ao migrar do campo para a cidade.

Turnes (2008) acredita que os subsídios, os incentivos econômicos e o aparato institucional mobilizados para a adoção de técnicas produtivas e culturas altamente poupadoras de mão-de-obra são certamente a razão principal de um êxodo tão intenso. Acreditava-se, segundo Menezes (2009) que praticamente nada poderia ser feito em relação ao êxodo rural, sendo que o esvaziamento dos campos era uma questão de tempo, experiência esta vivida pelos países desenvolvidos.

O espaço rural, conforme Bourscheidt et al. (2004) vem sofrendo alterações em sua funções e formas, especialmente devido à reestruturação de novas interações que se estabelecem com o espaço urbano.

O esvaziamento associado à conjugação de envelhecimento e da masculinização hoje representam a realidade do meio rural brasileiro. Em um estudo realizado por Rochadelli et al. (2008) sobre a expansão florestal na região do planalto serrano catarinense, numa perspectiva a partir do perfil socioeconômico dos proprietários rurais verificou que grande parte dos proprietários tem idade superior a 50 anos, vive em pequena ou média propriedade e que o êxodo rural de jovens é intenso nesta região.

Conforme Camarano \& Beltrão (2000), o êxodo rural nos últimos 50 anos, pode ser observado pelo decréscimo de $68,8 \%$ para $22 \%$ de pessoas que residem nas áreas rurais.

O Rio Grande do Sul viveu a partir do inicio do século XX a decadência econômica da chamada Metade Sul do Rio Grande do Sul em contraposição ao crescimento agrícola e industrial da região norte do estado. Esta porção territorial é caracterizada como "Região de expulsão" apesar de ocupar mais de $50 \%$ do território gaúcho (ALBUQUERQUE, 2003). Segundo Batista et al (2005) atualmente esta região enfrenta dificuldades econômicas e sociais como conseqüência dos problemas enfrentados pelo setor agropecuário.

Calcanhotto (2001) complementa que nos municípios submetidos a menor pressão econômica a tendência é que as atividades agropecuárias desenvolvam-se com menor exigência de mão-de-obra.

Embora com uma produção agrícola bastante diversificada, com destaque conforme dados da Prefeitura Municipal de São Gabriel (2013), na produção da soja, arroz e milho, com áreas plantadas equivalente a $32.000 \mathrm{ha}, 30.000 \mathrm{ha}$ e $3.000 \mathrm{ha}$, respectivamente, e com uma pecuária centrada no rebanho bovino e ovino, o município se ressente da expulsão do homem rural em busca das melhores condições do espaço urbano. A diversificação de culturas, recentemente, implantada com o desenvolvimento da piscicultura e da apicultura, além da fruticultura a qual conta com o apoio do Executivo Municipal através de convênios são propostas que pretendem envolver as famílias no meio rural.

Considerando-se o exposto, busca-se com a presente pesquisa avaliar e buscar subsídios sobre o êxodo rural, em São Gabriel, município da Fronteira-Oeste do Estado do Rio Grande do 
Sul. Considera-se que os resultados da mesma podem ser importantes no sentido de desencadear reflexões, ampliar discussões e mover ações de gestores públicos, para esta parcela significativa da população.

\section{MATERIAL E MÉTODOS}

A pesquisa caracteriza-se como quantitativa, descritiva, exploratória, estudo de caso, realizada no município São Gabriel, Fronteira-Oeste do Rio Grande do Sul, fazendo parte do Bioma Pampa, e pertencente à Metade Sul do estado apresenta atualmente, cerca de 60 mil habitantes.

Os participantes da pesquisa foram trinta e sete (37) agricultores que abandonaram o campo que, voluntariamente, aceitaram participar da mesma. Para a coleta de dados foi utilizado um questionário criado pelos autores, composto por 26 perguntas fechadas, envolvendo informações sociodemográficas e questões sobre a situação em que se encontram hoje relacionando com as vividas no campo.

Os dados foram coletados no período de junho a dezembro do ano de 2009. Os trabalhadores, após aceitarem participar da pesquisa, receberam uma breve explanação sobre a mesma, destacando objetivos e garantindo segurança quanto à preservação da identidade dos mesmos. Foram atendidos os aspectos éticos da Resolução 196/96 do Conselho Nacional de Saúde, pois os trabalhadores foram convidados a assinar um Termo de Consentimento Livre e Esclarecido, em duas vias, ficando uma em poder deles e outra dos pesquisadores. Foi garan- tido aos mesmos que não correriam risco algum, nem teriam custos e/ou benefícios monetários ao integrarem-se à população pesquisada e que poderiam desistir da mesma a qualquer momento, se desejassem. Os dados foram analisados com o software estatístico SPSS e estatística descritiva.

\section{RESULTADOS E DISCUSSÃO}

Segundo os dados censitários do IBGEInstituto Brasileiro de Geografia e Estatística, o município de São Gabriel apresentou no período de 1940 -2010, um acréscimo em sua população urbana passando de, aproximadamente, 17.000 habitantes em 1940 para 52.000 habitantes, no ano de 2000.

Observando-se a Figura 1 nota-se que existe um constante aumento da população urbana, ocasionado, principalmente, pelo fluxo migratório no sentido rural-urbano. No fim da década de 60 é quando ocorre a quase equivalência do número de habitantes nos dois meios, mantendo-se a tendência de fluxo, porém, com maior intensidade. No ano de 2000 a população rural é aproximadamente $17 \%$ da população de São Gabriel.

Dados apresentados por Camarano \& Beltrão (2000), apontam o ano de 1970 com o maior registro de habitantes rurais no Brasil, correspondendo a $44 \%$ da população total. A partir desta data tem ocorrido um declínio populacional constante no meio rural, atingindo em 1996 os valores equivalentes a $22 \%$ do total da população brasileira.

A migração ocorrida na região estudada

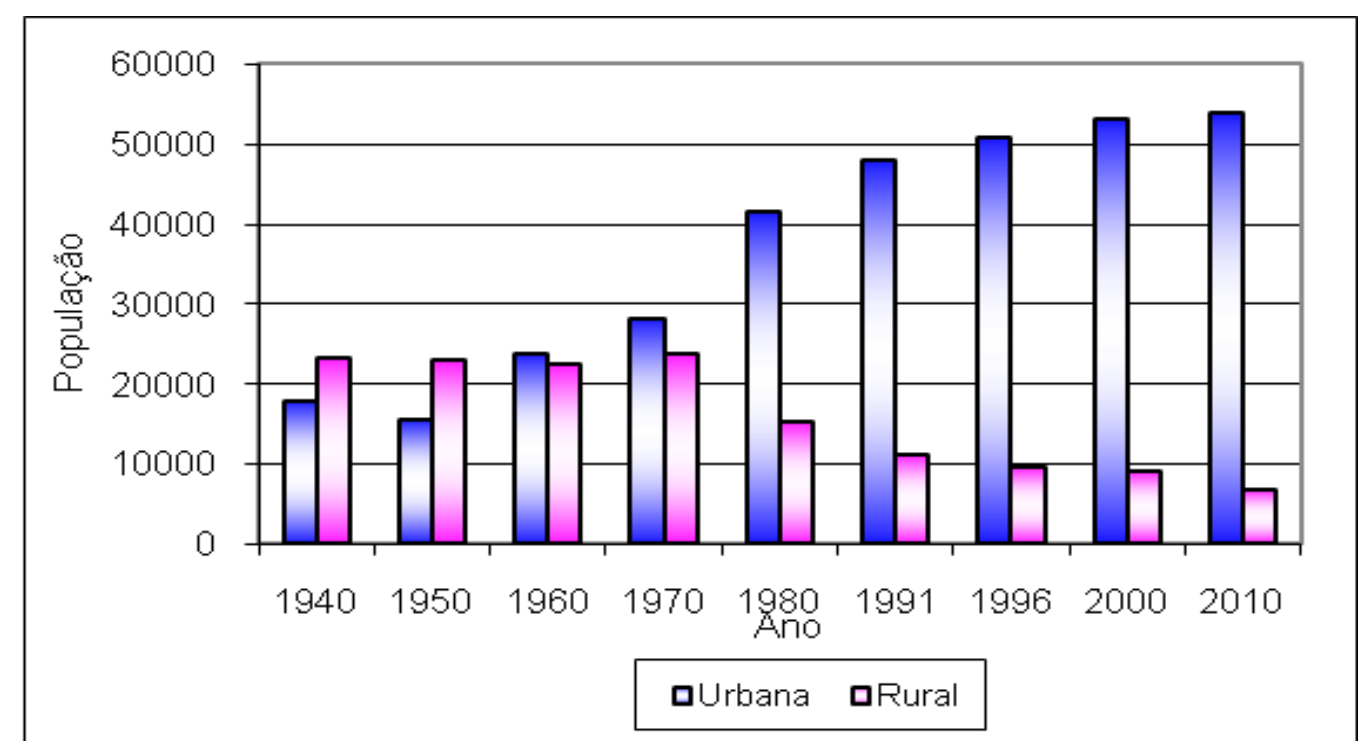

Figura 1: População Urbana e Rural de São Gabriel -RS de 1940 a 2010

Fonte: IBGE (2010) 
Tabela 1 - Características sociodemográficas dos pesquisados

\begin{tabular}{l|c|c}
\hline Característica & Empregado n(\%) & Autônomo \\
\hline Estado Civil & & \\
$\quad$ Solteiro & $2(9,5)$ & - \\
Casado & $4(19,0)$ & $8(50,0)$ \\
Viúvo & $13(61,9)$ & $2(12,4)$ \\
Separado/Desquitado & $2(9,5)$ & $3(18,8)$ \\
Relação Estável & - & $3(18,8)$ \\
\hline Local de Nascimento & $2(9,5)$ & $5(31,3)$ \\
Zona Urbana & $19(90,5)$ & $11(68,8)$ \\
Zona Rural & & $3(18,8)$ \\
\hline Situação da Residência & $4(19,0)$ & $13(81,2)$ \\
Alugada & $17(81,0)$ & \\
Própria & & \\
\hline
\end{tabular}

configura migrações municipais, onde o município, conforme Menezes (2001) é a unidade de referência e o lugar de recebimento desta população.

A análise do instrumento apontou que as pessoas que outrora desenvolviam suas atividades no meio rural e se deslocaram para a cidade de São Gabriel podem ser divididas em duas categorias quanto às atividades, ora desenvolvidas, ou seja: empregados e autônomos, conforme Tabela 1.

Dentre os entrevistados hoje empregados a maioria $(61,9 \%)$ são viúvos, seguido por um percentual de $19 \%$ casados enquanto dentre os que desenvolvem as atividades como autônomos, predominam os casados (50\%).

Todos apontaram o local de nascimento a zona rural o que demonstra o apego e o conhecimento da vida e das tarefas do campo. Um dado positivo dos novos moradores urbanos é o fato que $81 \%$ tanto de empregados como autônomos possuem residência própria, contrariando a literatura que relata a marginalização destes indivíduos (MENEZES, 2001).

Santos (2008) coloca que para cidadãos que buscam a cidade e que acabam, muitas vezes contribuindo para a expansão das periferias a conquista da casa própria se sobrepõem a necessidade de água tratada ou a presença de rede de esgoto, caracterizando um critério relativo e pessoal.

A realidade vivenciada pelos entrevistados quando moradores do meio rural e as condições de vida no ambiente urbano são apresentados na Tabela 2 com os entrevistados autônomos e na Tabela 3 com os entrevistados empregados.

Dentre os hoje trabalhadores autônomos a maioria possuía seus próprios bens com propriedades com área inferior a 100 ha. Dentre os proprietários cerca de $40 \%$ possuíam áreas que variavam entre 100 e 400 ha.

A falta de implementos agrícolas apontado por $75 \%$ dos entrevistados autônomos talvez seja um dos motivos do afastamento das atividades agrícolas. Conforme Pontes (2004), o setor de máquinas agrícolas é um difusor de progresso técnico, porém na década de 90 houve a retração nas vendas de máquinas agrícolas, reduzindo, principalmente, a frota de tratores, motivado pelo mercado interno de maquinário desaquecido em virtude da insuficiência de capital por parte dos agricultores, descapitalizados e incertos com os rumos da economia.

O rompimento do vinculo destes trabalhadores com o meio rural é traduzido por não possuírem mais terras, situação de $87,5 \%$ dos entrevistados. Para Soares (2004) uma estrutura fundiária concentrada, somado a políticas públicas e padrões tecnológicos excludentes são as razões levaram ao empobrecimento dos agricultores, e por conseqüência, a perda de suas propriedades.

Embora longe de suas origens $75 \%$ dos mesmos possuem condições de manter o nível de 
Tabela 2 - Características do entrevistado autônomo

\begin{tabular}{l|c}
\hline Características & n (\%) \\
\hline A propriedade (terra) era: & $13(81,2)$ \\
Própria & $3(18,8)$ \\
Arrendada & \\
\hline Número de hectares que possuía na propriedade: & $8(50,0)$ \\
Menos de 100 & $6(37,6)$ \\
$100 \mid--400$ & $2(12,4)$ \\
Mais de 400 & $2(12,5)$ \\
\hline Possuía maquinário adequado para atividades agrícolas: & $12(75,0)$ \\
Sim & $2(12,5)$ \\
Não & $2(12,5)$ \\
Razoavelmente & $14(87,5)$ \\
\hline Atualmente ainda possuem área de terra: & $11(68,8)$ \\
Sim & $5(31,2)$ \\
Não & $13(81,3)$ \\
\hline Algum membro da família possui emprego fixo: & $3(18,7)$ \\
Sim & $2(12,5)$ \\
Não & $2(12,5)$ \\
\hline Principal fonte de renda da família atualmente: & \\
Trabalho fixo & \\
Trabalho eventual & \\
\hline Atualmente, a renda da família é suficiente para manter o mesmo \\
nível de vida de quando eram agricultores: \\
Sim & \\
Não & \\
Em parte & \\
\hline & \\
\hline & \\
\hline
\end{tabular}

vida, baseado na renda fixa da família. Este é um fator positivo, pois conforme Santos (2008) em razão do crescimento das cidades resultando em alterações, os espaços podem levar a deterioração da qualidade de vida dos moradores.

Dentre os entrevistados ora empregados (Tabela 3) cerca de 57\% dos mesmos desenvolvia atividades diversas na propriedade rural as quais incluíam tanto a agricultura, pecuária, culturas permanentes, produção hortigranjeira, manutenção do maquinário,cercas entre outras, enquanto os restantes exerciam atividades ligadas a agricultura e pecuária.

Ao se instalar na cidade os entrevistados desta categoria já apresentam características pró- prias do migrante onde $28,6 \%$ possuem trabalho temporário e 9,5\% eventual. Esta situação é apoiada por Menezes (2001) que aponta como característica do migrante, pela falta de opções, a aceitação de condições de trabalho que burlam seus direitos tendendo a clandestinação das relações trabalhistas e conduzindo ao barateamento da mão de obra.

Embora $42 \%$ tenham afirmado ser possível manter um padrão de vida familiar, observa-se que somente $42 \%$ dos demais membros da família mantêm trabalho fixo.

Para Staduto et al. (2004), alguns fazendeiros acreditam que a mão-de-obra temporária constitui um sério problema pelos custos e obrigações para os estabelecimentos, não gerando 
Tabela 3 - Características do entrevistado empregado

\begin{tabular}{l|c}
\hline \multicolumn{1}{c|}{ Características } & $\mathbf{n}(\mathbf{\%})$ \\
\hline Principal atividade que exercia: & $6(28,6)$ \\
$\quad$ Trabalho com agricultura em latifúndio & $3(14,3)$ \\
Trabalho com pecuária em latifúndio & $12(57,1)$ \\
Outros & \\
\hline Algum membro da família possui emprego fixo: & $9(42,9)$ \\
Sim & $12(57,1)$ \\
Não & \\
\hline Principal fonte de renda de sua família atualmente: & $7(33,3)$ \\
Trabalho fixo & $6(28,6)$ \\
Trabalho temporário & $2(9,5)$ \\
Trabalho eventual & $6(28,6)$ \\
Outro & \\
\hline Atualmente, a renda média mensal da família é suficiente & \\
para manter o mesmo nível de vida que tinham quando & \\
eram agricultores. & $9(42,8)$ \\
Sim & $6(28,6)$ \\
Não & $6(28,6)$ \\
Em parte & \\
\hline
\end{tabular}

compromisso e também deve ser considerando a baixa qualidade da força de trabalho empregada. Do ponto de vista da qualidade dos serviços poderá haver um comprometimento pela rotatividade da mão-de-obra.

As dificuldades enfrentadas pelos migrantes, caracterizada pela reciprocidade de impactos cujas relações sociais ora, são conflitantes e, ora são agregantes são apresentadas nas Tabelas 4 e 5 .

O sujeito ao migrar pode ter suas relações na sociedade e para com a natureza, melhoradas ou não. Como as migrações resultam em transformações o ato de migrar pode ser concebido como ganho ou perda do ponto de vista social, econômico e político (FONSECA, 2010).

A maior dificuldade apontada entre os entrevistados empregados (Tabela 4) foi o acesso dos filhos a escola onde $66,7 \%$ depararam-se com esta situação.

Para Dalberio (2008), as escolas públicas anunciam que há vaga para todos, porém a realidade brasileira reflete a exclusão social e educa-

Tabela 4 - Dificuldades do pesquisado como empregado

\begin{tabular}{l|c|c|c}
\hline \multicolumn{1}{c|}{ Em relação as dificuldades com: } & $\begin{array}{c}\text { Muita } \\
\text { Dificuldade }\end{array}$ & $\begin{array}{c}\text { Pouca } \\
\text { dificuldade }\end{array}$ & $\begin{array}{c}\text { Nenhuma } \\
\text { dificuldade }\end{array}$ \\
\hline Relacionamento com os colegas & - & $4(19,0)$ & $17(81,0)$ \\
Relacionamento com os patrões & - & $7(33,3)$ & $14(66,6)$ \\
Dificuldades salariais & $5(23,8)$ & $14(66,7)$ & $2(9,5)$ \\
Dificuldade de escola para os filhos & $14(66,7)$ & $5(23,8)$ & $2(9,5)$ \\
\hline
\end{tabular}


Tabela 5 - Dificuldades do pesquisado como autônomo

\begin{tabular}{l|c|c|c} 
Dificuldades & $\begin{array}{c}\text { Muita } \\
\text { Dificuldade }\end{array}$ & $\begin{array}{c}\text { Pouca } \\
\text { dificuldade }\end{array}$ & $\begin{array}{c}\text { Nenhuma } \\
\text { dificuldade }\end{array}$ \\
\hline Venda da produção & - & $5(31,2)$ & $11(68,8)$ \\
Água & - & $3(18,8)$ & $13(81,2)$ \\
Mão de obra qualificada & $2(12,5)$ & $5(31,2)$ & $9(56,3)$ \\
Falta de incentivo governamental & $8(50,0)$ & - & $8(50,0)$ \\
Maquinário sucateado & - & $4(25,0)$ & $12(75,0)$ \\
Instabilidade climática & $5(31,2)$ & $4(25,0)$ & $7(43,8)$ \\
Transporte da produção & $2(12,5)$ & $5(31,2)$ & $9(56,3)$ \\
Escola para os filhos & $0(0)$ & $10(62,5)$ & $6(37,5)$ \\
Baixo retorno da produção & $5(31,2)$ & $3(18,8)$ & $8(50)$ \\
Falta de capital de giro & - & $10(62,5)$ & $6(37,5)$ \\
Preço dos insumos & $6(37,5)$ & $2(12,5)$ & $8(50,0)$ \\
\hline
\end{tabular}

cional. As escolas, além de faltar com a qualidade de ensino, não tem conseguido cumprir a sua função de ensinar a toda diversidade de alunos que o cotidiano apresenta.

O relacionamento com os colegas e patrões foi caracterizado pela maioria como sem nenhuma dificuldade. Este é sem dúvida um ponto positivo, pois toda a relação de emprego possui caráter bilateral, tanto no que tange a prerrogativas como a deveres, os quais se configuram quando uma relação jurídica se constitui.

Dos pesquisados empregados, $23 \%$ manifestou ter havido muita dificuldade em relação aos salários ofertados enquanto $66,7 \%$ apontaram ter encontrado pouca dificuldade. "O impacto da migração sobre os diferenciais salariais na região de destino depende de como a distribuição de habilidades dos migrantes pode ser comparada à distribuição de habilidades da população não-migrante." (FREGUGLIA, 2001, p.29)

Os entrevistados autônomos apresentaram (Tabela 5) como a maior dificuldade a falta de incentivos governamentais seguido pelo preço dos insumos. Esta situação se fundamenta na dificuldade dos pequenos produtores obterem crédito associado a falta de garantia no preço mínimo dos produtos e a constante ameaça da entrada de produtos importados. O processo de modernização da agricultura segundo Delgado apud Teixeira (2005) é uma das razões da exclusão de grupos sociais do campo e que também não contribui para reduzir o distanciamento entre o pequeno e o grande produtor.

Fatores como a presença de água, venda e transporte da produção não foram apresentados como dificuldades enfrentadas.

Em torno de $62 \%$ dos entrevistados apontaram alguma dificuldade no que tange a falta de capital de giro e a inserção dos filhos nas escolas. Nas palavras de Dalberio (2008) a escola precisa cumprir a sua função social, pois a democracia da educação dar-se-á não apenas pela garantia de acesso à escola, mas também da permanência do educando. Segundo Menezes (2009) para que o jovem rural não precise optar entre trabalho rural ou educação é necessário a promoção do desenvolvimento rural, para que este possa ter acesso à educação no seu espaço de origem.

Os resultados da presente pesquisa confirmam as ponderações de Hassler (2006) de que a vinda das famílias para a cidade foi envolta em uma expectativa de mudança de vida. Nas palavras do autor não se pode afirmar que tenham se iludido, mas perceberam algumas dificuldades em realizar algumas conquistas e desfrutar os confortos sonhados.

Nesta pesquisa (Tabela 6), observou-se que mais da metade dos entrevistados afirma que a qualidade de vida em relação a alimentação, transporte, ensino, moradia, saúde, vestuário e lazer, permaneceu igual ou melhorou com a sua transferência para o meio urbano tanto para o empregado como para o autônomo.

Para Minayo et al. (2000) a qualidade de 
Tabela 6- Comparação da qualidade de vida entre a situação rural e na cidade.

\begin{tabular}{l|c|c|c|c|c}
\hline & \multicolumn{3}{|c|}{ Empregado } & \multicolumn{2}{c}{ Autônomo } \\
& $\begin{array}{c}\text { Piorou } \\
\text { n (\%) }\end{array}$ & $\begin{array}{c}\text { Permaneceu } \\
\text { igual n (\%) }\end{array}$ & $\begin{array}{c}\text { Melhorou } \\
\text { n (\%) }\end{array}$ & $\begin{array}{c}\text { Permaneceu } \\
\text { igual n (\%) }\end{array}$ & $\begin{array}{c}\text { Melhorou } \\
\text { n (\%) }\end{array}$ \\
\hline Alimentação & $9(42,8)$ & $5(23,8)$ & $7(33,3)$ & $5(31,2)$ & $11(68,8)$ \\
Transporte & - & $13(61,9)$ & $8(38,1)$ & $3(18,8)$ & $13(81,2)$ \\
Ensino & $4(19,0)$ & $17(81,0)$ & - & - & $16(100)$ \\
Moradia & $2(9,5)$ & $4(19,0)$ & $15(71,4)$ & $3(18,8)$ & $13(81,2)$ \\
Saúde & - & $2(9,5)$ & $19(90,5)$ & - & $16(100)$ \\
Vestuário & - & $6(28,6)$ & $15(71,4)$ & - & $16(100)$ \\
Lazer & $3(14,3)$ & $7(33,3)$ & $11(52,4)$ & - & $16(100)$ \\
& & & & & \\
\hline
\end{tabular}

vida é um conhecimento distinto do ser humano, que se aproxima ao nível de satisfação encontrado na vida, relacionando a convivência familiar, amorosa, social e ambiental podendo ser considerado como padrão de conforto e bem-estar.

\section{CONCLUSÕES}

As relações de trabalho impostas ao homem do campo nas últimas décadas no século passado promoveu mudanças tanto no cenário rural como urbano.

O êxodo rural vivenciado em São Gabriel/ RS demonstrou que a maioria dos entrevistados, tanto empregados como autônomos, embora tenham encontrado dificuldades, nos dias atuais possuem casa própria.

Os dois grupos apontaram a dificuldade de inserção dos filhos nas escolas o que demonstra lacunas na oferta de vagas pelas escolas municipais e estaduais.

A pesquisa revela que mesmo diante do acentuado êxodo rural ocorrido estes migrantes buscaram condições de vida digna para suas famílias e a formação de ambientes para a construção de sua cidadania.

\section{REFERÊNCIAS BIBLIOGRAFICAS}

ALBUQUERQUE, P. P. Metade Sul: um espaço de ações propositivas. Porto Alegre: OCERGS, 2003.

BALSAN, R. Impactos decorrentes da modernização da agricultura brasileira. Campo-território: Revista de geografia agrária, v. 1, n. 2, p. 123-151, 2006.
BATISTA, I. M.; SILVEIRA, V. C. P; ALVES, F. D. As desigualdades regionais no Rio Grande do Sul e o setor agropecuário: uma analise econômica. In: CONGRESSO INTERNACIONAL DE DESENVOLVIMENTO RURAL E AGROINDUSTRIA FAMILIAR. São Luiz Gonzaga, 2005. Anais... Santa Maria, CIDRAF, 2005, p.943-950.

CAMARANO, A. A. \& BELTRÃO, K. I. Distribuição espacial da população brasileira: mudanças na segunda metade deste século. Rio de Janeiro: IPEA, 2000. (Texto para Discussão No 776 ).

CALCANHOTTO, F. A. Diagnóstico e Análise de Sistemas de Produção no Município de. Guaíba/RS: uma abordagem agroeconômica. 2001. 209 p. Dissertação (Mestrado em. Economia Rural) - UFRGS, Porto Alegre.

DALBERIO, M. C. B. Gestão democrática e participação na escola pública popular. Revista Iberoamericana de Educación. Organización de Estados Iberoamericanos para la Educación, la Ciencia y la Cultura (OEI) n. 47/3, 2008.

FONSECA, G. S. Espacialização das migrações temporárias de mirabelenses. In: ENCONTRO NACIONAL DE ESTUDOS POPULACIONAIS. Caxambu, 2010. Anais... ABEP: Caxambu, 2010.

FREGUGLIA, R. da S. Migração e salários no Brasil formal. Informações FIPE, 2001. p. 29.

HASSLER, M. L. O êxodo rural como fator de ocupação territorial no bairro São José de PassoFundo/ RS. Estudos Geográficos, v. 4, n.1, p. 23-30, 2006. 
MENEZES, I. G. Enxada versus caneta: educação como prerrogativa do urbano no imaginário de jovens rurais. Revista Eletrônica de Educação. São Carlos, SP: UFSCar, v.3, n. 1, p. 24-38, 2009.

MENEZES, M. L. P. A crise do estado de bem estar e a caracterização de processos territoriais da migração no Brasil. Scripta Nova.

Revista Electrónica de Geografía y Ciencias Sociales. Universidad de Barcelona. n.94 ,v.85, 2001. Disponivel em: www.ueb.es./geocrit/Sn-94-84.htm. Acesso em: 02 nov. 2010.

MINAYO, M. C. S.; HARTZ, Z. M. A.; BUSS, P. M. Qualidade de vida e saúde: um debate necessário. Ciência \& Saúde Coletiva, v. 5, n.1, p. 7-18, 2000.

MORAIS, E. P. Envelhecimento no meio rural: condição de vida, saúde e apoio dos idosos mais velhos de Encruzilhada do Sul -RS. Tese (Doutorado em Enfermagem Fundamental) Ribeirão Preto. Universidade de São Paulo. 215 f. 2007.

Prefeitura Municipal de São Gabriel Disponível em <http://www.saogabriel.rs.gov.br/2013/conheca/ economia.html> Acesso em: 06 de abril de 2013;

PONTES, N. R. Avaliação dos impactos e transformações do programa MODEFROTA na industria de maquinas agrícolas: caso AGCO. 2004. 118p. (Mestrado em Administração) UFRGS, Porto Alegre, 2004.

ROCHADELLI, R.; MENDES, R.H.; SCHNEIDER, V.; MENON, C. R.; AUGUSTIN, C. R. Expansão florestal na região do planalto serrano catarinense: uma perspectiva a partir do perfil socioeconômico dos proprietários rurais. FLORESTA, v. 38, n. 3, p. 459-464, 2008.

ROTH, J. D.; WESZJUNIOR, V. J.; MATTOS, V. M. M.; BUENO, V. de N.; FERREIRA, A. M. R. M. Jovens agricultores gaúchos na Suíça: novas fronteiras de trabalho? Desenvolvimento em questão. n.7, p. 169-183, 2006.

SANDRONI, P. Novíssimo Dicionário de Economia. São Paulo: Editora Best Seller, 1999.

SANTOS, D. G. Qualidade ambiental urbana e ocupação periférica e percepção em área de proteção e recuperação de mananciais, zona sul de são Paulo. Caminhos de Geografia, v. 9, n. 26, p. 17-30, 2008.
SCHEIDT, V. et al. O espaço rural do distrito de Arroio Grande: uma perspectiva para o desenvolvimento regional. In: II SEMINÁRIO INTERNACIONAL SOBRE DESENVOVIMENTO REGIONAL, II. 2004,Santa Cruz do Sul. Anais.... Santa Cruz do Sul : PPGDR, 2004.

SOARES, P. P. D. Por um Brasil rural com reforma agrária. Revista de UFG- Tema Brasil Rural. v. 7, n. 1, 2004 Disponível em: WWW.proec.ufg.br Acesso em 23.out.2010.

STADUTO, J. A. R.; SHIKIDA, P. F. A.; BACHA, C. J. C. Alteração na composição da mão-de-obra assalariada na agropecuária brasileira. Agricultura em São Paulo, v. 51, n. 2, p. 57-70, 2004.

SULZBACHER, A. W. \& DE DAVID, C. Alternativas para o espaço rural: importância de compatibilizar políticas públicas com saberes locais. CAMPO-TERRITÓRIO: Revista de geografia agrária, v. 3, n. 5, p. 14-37, 2008.

TEIXEIRA, J. C. Modernização da agricultura no Brasil: impactos econômicos, sociais e ambientais. Revista Eletrônica da Associação dos Geógrafos Brasileiros - Seção Três Lagoas,v. 2, n. 2, p. 21-43, 2005.

TURNES, V. A. Reflexões sobre fluxos migratórios internos de populações no estado de Santa Catarina. Revista Brasileira de Gestão e Desenvolvimento Regional v. 4, n. 1, p. 155-194, 2008. 